\title{
Subjective Risk Tolerance of South African Investors
}

\author{
Zandri Dickason-Koekemoer, Suné Ferreira \\ North West University, South Africa \\ 20800274@nwu.ac.za
}

\begin{abstract}
In general, the amount of risk an individual is willing to tolerate can be influenced by demographic factors. However, needs for research arise as to whether demographic factors influence the amount of risk investors in South Africa are willing to tolerate. The survey was conducted in 2017 and all South African investors were included in the sample frame. For this study, a sample of 800 was collected and used. Multinomial regression was used to indicate whether there were more than two factors that can influence the four risk tolerance levels of South African investors. The study suggested that gender is a determining factor in the risk tolerance of individuals. African investors were more likely to take the substantial financial risk. Age was also a determining factor of risk tolerance which follows the assumptions of the investor lifecycle where younger investors are more risk tolerant. The study furthermore found that higher annual income attracts more risk-taking while lower-income attracts more risk averseness in individuals. It was lastly observed that married individuals and those that are no longer married will be more likely to be risk-averse. This study makes a significant contribution in profiling investors risk tolerance according to their demographic factors whereby financial institutions can offer more tailored investment options.
\end{abstract}

Keywords: Subjective risk tolerance, demographics, investments, South African investors

\section{Introduction}

Due to the unpredictability and uncertainty of the future, the risk is created from uncertainty. The risk that arises from uncertainty can potentially be managed (Crouhy et al., 2014). People encounter risk in everyday life. Risk can be explained in terms of investment where as a result of uncertainty regarding future returns or potential losses, the risk is created (Van den Berg, 2004). However, risk and uncertainty do not concur (Rachev et al., 2011). The continuation of risk is known as a situation or rather, a group of situations, in which a probability of loss occurs that generates uncertainty on behalf of the individual (Vaughan \& Vaughan, 2008). Individuals' determine the amount of risk they are willing to tolerate or accept for a given period of time. The main aim is to identify the possible causes of risk in order to accurately manage and control these risks (Old Mutual, 2015). The outcome probabilities are known for investment decisions made under risk whereas the outcome probabilities are unknown for investment decisions made under uncertainties (Goldstein \& McElligott, 2014). A relationship has been identified between risk perception, risk propensity and risk-taking behaviour of investors. From this it could be gathered that investors can take a certain amount of risk comfortably when making investment decisions.

These risks of investors are composed out of risk appetite and risk capacity. It can be concluded that investors can tolerate a certain amount of risk when making investment decisions. During the 1900's, Tversky and Kahneman (1981) stated that risk tolerance should be used as the dependent variable and other factors as independent variables. From previous studies conducted by Van de Venter et al. (2012) and Nguyen (2015) risk tolerance can be influenced by socio-economic, demographic and psychological factors. The amount of risk an individual is willing to tolerate can be influenced by demographic variables (MacCrimmon \& Wehrung, 1986). However, needs for research arise as to whether demographic factors influence the amount of risk investors in South Africa are willing to tolerate. Previous research done by Dickason and Ferreira (2018) found that gender and age do influence investors risk tolerance. A study by Van Dorresteijn (2017) also found that marriage status influence risk tolerance where unmarried individuals were more willing to accept risks than married individuals. The University of Missouri-Columbia (2017) confirmed that gender has an influence where male investors were more tolerant of financial risks than female investors.

\section{Literature Review}

Rutgers (2014) stated that risk tolerance is one of the most important concepts in the financial industry and a fundamental factor that should be taken into account when planning investment strategies for individuals. 
Risk tolerance is commonly referred to an investor's attitude towards risk (Sahin \& Yilmaz, 2009). Moreover, Grable (2000) defined risk tolerance as a degree of uncertainty in investment returns which an individual investor is willing to accept. Davey and Resnik (2008) stated that risk tolerance is the amount of risk individuals are willing to take when exploring unfavourable outcomes with possible favourable outcomes in the future. Risk tolerance can ultimately be divided between subjective and objective risk tolerance (Hanna \& Chen, 1997). Subjective risk tolerance is known by the economic theory of risk aversion whereas objective risk tolerance based on Malkiel's notion of the objective financial situation of households including investment goals' horizon (Malkiel, 1996). According to Hanna et al. (2001) risk tolerance can be measured by four measures namely to determine the individual investors' investment choices, to ask a combination of investment and subjective questions, to evaluate actual behaviour and to assess specific scenarios in terms of asking hypothetical questions. Risk tolerance can influence both short- and long-term goals of individual investors. The method of investing in short- (savings) and long-term (retirement) is influenced by risk tolerance (Grable, 2016). Risk tolerance incorporates risk requirement, risk capacity and risk preference of investors and this can be measured by how investors perceive risk (Louw, 2017). Hence if an investor is willing to take high risk, the question remains if it is to generate a high return or a reflection of a lack of financial knowledge (Louw, 2017). Numerous factors can impact risk tolerance levels of investors whilst making investment decisions.

As a result, risk tolerance levels of investors are regarded as the dependent variable. Irwin (1993) explained that demographic factors (i.e. age, income, gender, ethnicity, marital status) can influence the level of risk an investor is willing to tolerate. Sung and Hanna (1996) highlight from previous research that demographic factors such as education levels, ethnicity, employment status, gender, other income and age can possibly influence financial risk tolerance. Previous researchers such as Wang and Hanna (1997) found that there is a relationship between age and risk tolerance; whereas, Grable and Lytton (1998) found that the two most influential variables on risk tolerance are age and gender. Grable and Lytton continued with research in the field of financial risk tolerance and found that other factors such as marital status, education levels, financial knowledge, income levels, occupation and economic expectations also have an impact on the level of risk investors are willing to tolerate. In contradiction to the previous findings, Grable (2000) emphasised in research that gender, marital status and age are not considered important influences. Moreover, Mazumdar (2014) conducted a research study and concluded that no evidence exists of a relationship between financial knowledge and investment behaviour. Irwin (1993) indicated that young people are more risk tolerant than older people. It is believed that older people have time constraints to recover from financial losses due to making inaccurate investment decisions (Grable, 1997). Therefore, young people are willing to take on more financial risk as they have more time to recover from financial losses experienced due to inaccurate investment decisions (Grable \& Roszkowski, 2008; Gibson et al., 2013). Contrarily, researchers such as Botwinick (1966), Vroom and Pahl (1971), Baker and Haslem (1974), Okun and DiVesta (1976), Morin and Suarez (1983), Hawley and Fuji (1993), Wang and Hanna (1997), Grable (2000) and Van de Venter et al. (2012) found in their research that older people are willing to tolerate more risk.

No universal agreement is established as to whether gender, as a demographic factor, influence the level of risk an individual is willing to tolerate. Research done by Higbee and Lafferty (1972), Blume (1978), Coet and McDermott (1979), Rubin and Paul (1979) and Yip (2000) indicated that gender is an important influential factor of risk tolerance. Roszkowski et al. (1993), Hawley and Fuji (1993), Slovic (1966), Sung and Hanna (1996), Sharma (2006) and Rahmawati et al. (2015) reached a consensus that females take less risks than males, thus males are more risk tolerant than females. Cultural differences in terms of values, tastes and preferences can affect risk tolerance levels. The general norm is that White people are willing to tolerate more risk than non-White people. This norm is based on the accessibility of White people to banks and financial institutions, more future-oriented outlooks and more investment opportunities than non-White people. White people will therefore, portray an attitude of confidence in decision-making skills and their abilities to analyse (MacCrimmon \& Wehrung, 1986; Zhong \& Xiao, 1995; Sung \& Hanna, 1996). In South Africa a study was conducted between risk tolerance and ethnicity. Metherell (2011) found, based on research done, that a significant difference exists between White people and the Indian population. Moreover, Van Schalkwyk (2012), concluded in his study that African people tend to take higher risks than White people, thus making African people more risk tolerant. Marital status can be compartmented into married, never married, divorced, separated and widowed. It can be argued that married investors have more 
responsibilities in terms of households, dependants and spouses. The identified risk, social risk, are apparent for married investors as there can be a possible loss of self-esteem in social circles as financial losses can be a result of inaccurate investment choices (Roszkowski et al., 1993).

Researchers such as Baker and Haslem (1974), Lee and Hanna (1991), Lazzarone (1996), Sung and Hanna (1996) indicated that married investors tend to have a decreased investment risk appetite in comparison to unmarried investors. The general belief is that people with high gross incomes are more likely to take on high investment risks compared to lower gross income groups (Cohn et al., 1975). Moreover, a research study conducted by Warren et al. (1990) concluded that high-income males are more likely to invest in risky bonds and stocks than high-income females. A general consensus is reached between researchers such as Grable and Lytton (1998), Grable and Joo (1999), Grable (2000), Grable and Joo (2004), Ardehali et al. (2005), Gibson et al. (2013) and Rahmawati et al. (2015) that high-income individuals take on higher investment risks. The study of Rahmawati et al. (2015) aimed to determine the main determinants of the risk tolerance of individual investors in Pakistan. The study included the risk tolerance measurement of 187 participants.

\section{Methodology}

The influence of subjective financial risk tolerance on individual decisions are known over the world, however, subjective financial risk tolerance has not received a lot of attention in the South African context, specifically for investors. It is important to analyse the factors that can potentially influence the subjective risk tolerance of investors in order to understand their investment decisions. Previous research indicated that age, gender, income, marital status and ethnicity influence subjective risk tolerance levels of individuals. As a result, this study aimed to test whether these factors also influence the investment decisions of South Africa investors. A survey was electronically distributed to investors in South Africa.

Data: The survey was conducted in 2017 and all South African investors were included in the sample. For this study, a sample of 800 was collected and used. This sample is distributed over the nine provinces in South Africa. The study made use of purposeful sampling as the most productive sample has been included (Marshall, 1996; Quinlan, 2011; Creswell, 2014). The questionnaire was sent electronically to a South African investment company and the company reloaded the questionnaire onto a system that is used to interact with their clients. This electronic version of the questionnaire was distributed to the participants via the company's system and was returned electronically. The Survey of Consumer Finances (SCF) is a single risktolerance question. This scale continues to be widely used by researchers. The reason for this is that the measured item is the only direct measure of risk attitudes (Gilliam et al., 2010). The data analysis involves the use of a multinomial logistic regression. This regression is used to analyse the influential demographic factors that predict the subjective risk tolerance level of South African investors. A multinomial regression is used when there are more than two factors that can influence the four subjective risk tolerance levels of South African investors.

Therefore, the Multinomial Model can be defined as Follow:

$$
P_{i j} \frac{\exp \left(B_{j} X_{i}\right)}{1+\sum_{j=1}^{4} \exp \left(B_{j} X_{i}\right)} \text { for } j=1,2,3,4
$$

Where $\boldsymbol{X}_{\boldsymbol{i}}$ is the vector for the independent variables representing the demographic variables for each $\mathrm{i}^{\text {th }}$ investor profile. $\boldsymbol{B}_{\boldsymbol{j}}$ represents the vector for the regression estimates for each alternative $\boldsymbol{j}$ subjective risk tolerance level. The base category for each of the explanatory variables assumed to have a coefficient of zero when used as the reference group. The base category was chosen as follow:

$$
P_{i=} \frac{1}{X_{i}}=\frac{\exp \left(B_{j} X_{i}\right)}{1+\sum_{j=1}^{4} \exp \left(B_{j} X_{i}\right)}
$$

The probability of investors falling into one of the other subjective risk tolerance groups can be calculated as follow:

$$
P_{i=}(\mathbf{j}=\mathbf{m x})=\frac{\exp \left(B_{j} X_{i}\right)}{1+\sum_{j=1}^{4} \exp \left(B_{j} X_{i}\right)} \text { where } \mathbf{m}>1
$$


Therefore, the multinomial regression model to determine investors subjective risk tolerance levels according to their demographics can be defined as follow:

$$
P_{i j}=\operatorname{In}(P i j)=B_{0}+B_{1} X_{1 i}+B_{2} X_{2 i}+B_{3} X_{3 i} \ldots \ldots B_{n} X_{n i}+\varepsilon
$$

$\boldsymbol{P}_{\boldsymbol{i}}$ is the probability that investors might fall into any of the four subjective risk tolerance categories being, (1) not willing to take any financial risk (2) willing to take below average financial risk (3) willing to take above average financial risk and (4) willing to take suthe bstantial financial risk.

\section{Results and Discussion}

The following sections represent the descriptive statistics and regression analysis of the influence of demographic factors on investors' subjective risk tolerance levels.

Demographics of South African Investors' Subjective Risk Tolerance: Table 1 indicates the frequencies of South African investors according to their subjective risk tolerance, age, gender, marital status, annual income and ethnicity.

Table 1: Frequency of Dependant and Independent Variables

\begin{tabular}{lll}
\hline Variable & Category & Frequency \\
\hline Subjective risk tolerance & Not willing to take any financial risk & $21.5 \%$ \\
& Willing to take average financial risk & $43.9 \%$ \\
& Take above average financial risk & $26.1 \%$ \\
Age & Take substantial financial risk & $8.5 \%$ \\
& $16-34$ & $25.0 \%$ \\
Gender & $35-49$ & $35.8 \%$ \\
& $50+$ & $39.3 \%$ \\
Marital status & Male & $43.9 \%$ \\
& Female & $56.1 \%$ \\
Annual Income & Never married & $25.8 \%$ \\
& Married & $57.9 \%$ \\
& No longer married & $16.4 \%$ \\
& R100 000 or less & $15.4 \%$ \\
Ethnicity & R100 001-R300 000 & $36.1 \%$ \\
& R300 001-R500 000 & $22.8 \%$ \\
& R500 001-R700 000 & $13.6 \%$ \\
& More than R700 000 & $12.1 \%$ \\
& African & $17.5 \%$ \\
& White & $66.5 \%$ \\
\hline
\end{tabular}

Table 1 above reflect the frequencies of the dependent variable, subjective risk tolerance, as well as the five independent variables namely age, gender, marital status, income and ethnicity. The sample consisted of 800 investors where the majority (43.9\%) of investors indicated that they are only willing to take the average financial risk. Only 8.5 percent of the sample were willing to take the substantial financial risk. Merely, 25.0 percent of the investors were below the age of 34 years, where the majority of investors were older than 35 years. This is indicative that the sample consisted of older more experienced investors. More than half of the sample (56.1\%) were female investors while 43.9 percent represented male investors. Almost 60.0 percent were married, followed by 25.8 percent that has never been married and 16.4 percent investors that are no longer married. Considering the income distribution, the majority of investors earn between R100 001R300 000 per annum, whereas, only 12.1 percent earn more than R700 000 per annum. The sample consisted mainly out of White investors where this ethnicity group represented 66.5 percent of the sample. 
Table 2: Multinomial Logic Regression Results

\begin{tabular}{|c|c|c|c|c|c|c|c|}
\hline $\begin{array}{l}\text { Dependant } \\
\text { category }\end{array}$ & Variable & Beta & $\begin{array}{l}\text { Std. } \\
\text { Error }\end{array}$ & Wald & DF & Sig. & EXP (B) \\
\hline \multirow{13}{*}{$\begin{array}{l}\text { Willing to take } \\
\text { average } \\
\text { financial risk }\end{array}$} & Gender (Male) & 0.508 & 0.216 & 5.521 & 1 & 0.019 & 1.662 \\
\hline & African & 1.016 & 0.432 & 5.527 & 1 & 0.019 & 2.761 \\
\hline & White & 0.877 & 0.347 & 6.391 & 1 & 0.011 & 2.404 \\
\hline & $\begin{array}{l}\text { Coloured } \\
\text { Asian (Ref. group) }\end{array}$ & 0.344 & 0.451 & 0.580 & 1 & 0.446 & 1.410 \\
\hline & $16-34$ & 0.903 & 3.050 & 8.767 & 1 & 0.003 & 2.466 \\
\hline & $35-49$ & -0.169 & 0.224 & 0.569 & 1 & 0.451 & 0.845 \\
\hline & $50+$ (Ref. group) & & & & & & \\
\hline & $<\mathrm{R} 100000$ & -1.136 & 0.433 & 6.878 & 1 & 0.009 & 0.321 \\
\hline & R100 001-R300 000 & -0.634 & 0.397 & 2.544 & 1 & 0.111 & 0.530 \\
\hline & R300 001-R500 000 & -0.058 & 0.420 & 0.019 & 1 & 0.891 & 0.944 \\
\hline & $\begin{array}{l}\text { R500 001-R700 } 000 \\
\text { >R700 } 001 \text { (Ref. group) }\end{array}$ & -0.068 & 0.476 & 0.020 & 1 & 0.887 & 0.934 \\
\hline & Never married & 0.128 & 0.332 & 0.157 & 1 & 0.692 & 1.136 \\
\hline & $\begin{array}{l}\text { Married } \\
\text { No longer married (Ref. } \\
\text { group) }\end{array}$ & 0.493 & 0.258 & 3.651 & 1 & 0.056 & 1.637 \\
\hline \multirow{12}{*}{$\begin{array}{l}\text { Take above } \\
\text { average } \\
\text { financial risk }\end{array}$} & Gender (Male) & 1.071 & 0.240 & 19.896 & 1 & 0.000 & 2.917 \\
\hline & African & 0.677 & 0.470 & 2.071 & 1 & 0.150 & 1.968 \\
\hline & White & 0.489 & 0.381 & 1.645 & 1 & 0.200 & 1.631 \\
\hline & $\begin{array}{l}\text { Coloured } \\
\text { Asian }\end{array}$ & -0.088 & 0.513 & 0.030 & 1 & 0.863 & 0.915 \\
\hline & $16-34$ & 1.342 & 0.338 & 15.728 & 1 & 0.000 & 3.825 \\
\hline & $35-49$ & 0.281 & 0.259 & 1.177 & 1 & 0.278 & 1.324 \\
\hline & $50+$ & & & & & & \\
\hline & $<\mathrm{R} 100000$ & -1.948 & 0.456 & 18.264 & 1 & 0.000 & 0.143 \\
\hline & R100 001-R300 000 & -1.694 & 0.408 & 17.222 & 1 & 0.000 & 0.184 \\
\hline & R300 001-R500 000 & -1.095 & 0.432 & 6.444 & 1 & 0.011 & 0.334 \\
\hline & $\begin{array}{l}\text { R500 001-R700 } 000 \\
\text { >R700 } 001\end{array}$ & -0.548 & 0.480 & 1.302 & 1 & 0.254 & 0.578 \\
\hline & Never married & 0.738 & 0.384 & 3.686 & 1 & 0.055 & 2.092 \\
\hline \multirow{13}{*}{$\begin{array}{l}\text { Take } \\
\text { substantial } \\
\text { financial risk }\end{array}$} & Gender (Male) & 1.063 & 0.326 & 10.635 & 1 & 0.001 & 2.896 \\
\hline & African & 1.747 & 0.611 & 8.172 & 1 & 0.004 & 5.739 \\
\hline & White & -0.073 & 0.569 & 0.017 & 1 & 0.898 & 0.929 \\
\hline & $\begin{array}{l}\text { Coloured } \\
\text { Asian }\end{array}$ & -0.243 & 0.761 & 0.102 & 1 & 0.750 & 0.785 \\
\hline & $16-34$ & 1.887 & 0.476 & 15.700 & 1 & 0.000 & 6.600 \\
\hline & $35-49$ & 0.985 & 0.396 & 6.197 & 1 & 0.013 & 2.677 \\
\hline & $50+$ & & & & & & \\
\hline & $<\mathrm{R} 100000$ & -1.055 & 0.614 & 2.955 & 1 & 0.086 & 0.348 \\
\hline & R100 001-R300 000 & -1.076 & 0.558 & 3.724 & 1 & 0.054 & 0.341 \\
\hline & R300 001-R500 000 & -0.915 & 0.612 & 2.236 & 1 & 0.135 & 0.400 \\
\hline & $\begin{array}{l}\text { R500 001-R700 } 000 \\
>\text { >R700 } 001\end{array}$ & -0.416 & 0.663 & 0.393 & 1 & 0.531 & 0.660 \\
\hline & Never married & -0.651 & 0.477 & 1.861 & 1 & 0.173 & 0.522 \\
\hline & $\begin{array}{l}\text { Married } \\
\text { No longer married }\end{array}$ & -0.762 & 0.412 & 3.414 & 1 & 0.065 & 0.467 \\
\hline
\end{tabular}


Table 2 reflects the multinomial logistic results of the relationship between the independent demographic variables and the dependent variable, subjective risk tolerance. The results of the study are provided in Table 2 which indicates that the data fits the model as the p-value is not significant in both Pearson (0.462) and Deviance (0.585) goodness-of-fit tests. The Pseudo R-Squared statistic was used to assess the model fit and measure the predictive power of how well the dependent variable, in this case subjective risk tolerance, can be predicted based on the explanatory variables, age, gender, income, ethnicity and marital status. The results indicated a 19.2 percent variance in the subjective risk tolerance of an individual investor that is predictable from the demographical attributes. Previous literature suggests that gender is a determining factor in subjective risk tolerance of individuals. Hence, the results for this research study found an overall p-value for gender significant at the 1 percent level of significance. For the individual risk tolerance models willing to take average financial risk (0.019), above average financial risk (0.000) and substantial financial risk (0.001), a significant difference was found at 1 percent and 5 percent.

The dominant sign for gender was positive indicating that male investors are less likely to be in the reference category - not willing to take any financial risk. Therefore, the results concur with previous research by Higbee and Lafferty (1972), Blume (1978), Coet and McDermott (1979), Rubin and Paul (1979), Yip (2000), Roszkowski et al. (1993), Hawley and Fuji (1993), Sung and Hanna (1996). Sharma (2006) and Rahmawati et al. (2015) which suggested that males are more risk tolerant than females. For the independent variable ethnicity, an overall significant p-value $(0.000)$ at 1 percent was obtained. For the first model, willing to take the average financial risk, a significant difference at 5 percent was found for African (0.019) and White investors (0.011). For the third model, take the substantial financial risk, a significant difference (0.001) at 1 percent was observed for African investors. For all three models African investors were more likely to fall in the dependent category rather than in the reference category, not willing to take any financial risk. These results are similar to Van Schalkwyk (2012), who found African people to be more risk tolerant than other races. A negative coefficient was obtained for Coloured investors in two out of the three models indicating that Coloured investors are more likely to be risk-averse and not willing to take on any financial risk.

Concerning the age distribution, an overall significant p-value (0.000) at 1 percent was again obtained. For all three models, the age category 16-34 years was significant at 1 percent, whereas the age category 35-49 was only significant in the third model (0.013). Positive coefficients for age groups 16-34 and 35-49 were observed in all three models indicating that investors within these age categories are more likely to fall in the higher risk categories, compared to older investors $(50+)$ which are not willing to take on any financial risk. This correlates with research studies of Irwin (1993), Grable and Roszkowski (2008), Gibson et al. (2013) indicating that older investors tend to be more risk-averse and not willing to take on any financial risk while young investors are more willing to take on average to higher risk investments. For the independent variable annual income, an overall significant $p$-value $(0.000)$ at 1 percent was obtained. Previous literature by Grable and Lytton (1998), Grable and Joo (1999), Grable (2000), Grable and Joo (2004), Ardehali et al. (2005), Gibson et al. (2013) and Rahmawati et al. (2015) concluded that annual income plays an important role in the risk tolerance of individuals i.e. how much risk they are willing to tolerate. These previous results found that higher income attracts more risk-taking while a lower income attracts more risk averseness in individuals.

The results of this study indicate similar results. The income groups, less than R100 000 and R100 000 up to R300 000 were significant at all three models. Largely negative coefficients were found for these low-income groups indicating that investors earning less than R300 000 per annum are more likely to fall in the reference category of not willing to take on any risk. The theoretical reasoning behind these results that investors with less income are not willing to take on high-risk investments in fear of losing their investment. The other income groups higher than R300 000 but below R700 000 per annum were also more likely to fall in the reference category but a linear decline in the negative coefficients was observed as the annual income group became larger. Therefore, these groups were also less likely to take on substantially higher financial risk compared to the income group of R700 000 and more. The last coefficient was on marital status, with no 
longer married as the reference group. For marital status an overall significant p-value (0.005) at 1 percent was obtained. Previous studies by Baker and Haslem (1974), Lee and Hanna (1991), Lazzarone (1996), Sung and Hanna (1996) indicate contradicting opinions regarding the influence of marital status on subjective risk tolerance. For married investors a p-value significant at 10 percent was found at all three models indicating a difference between married investors and investors that are no longer married.

\section{Conclusion}

The dominant sign for both never married and married investors were positive in the first two models indicating that these investors are more likely to take on average to higher risk than to be risk-averse, not willing to take on any risk. However, a larger positive coefficient was observed for never married investors. In the last model a negative coefficient was observed indicating that married investors and those that are no longer married will be more likely to be risk-averse. However, no significant difference was found at 1 percent or 5 percent. In a financial context, the amount of risk an individual is willing to accept is known as subjective financial risk tolerance. Previous research indicated that demographic factors can potentially influence the subjective risk tolerance levels however this has not been tested in a South African context. As a result, the primary objective of this study was to determine whether demographic factors influence the subjective risk tolerance levels of South African investors.

The survey method was used for this study of which the survey was conducted in 2017 and investors in the nine South African provinces were included. The sample size for this study was 800, thus the data of 800 investors were used. The risk tolerance levels of South African investors were divided into four levels and this study made use of the multinomial regression to indicate whether more than two factors can actually influence the risk tolerance levels of South African investors. Previous international studies concluded that more than two factors can influence the risk tolerance levels of investors and this was put to the test for a South African perspective. Results from this study indicated that African investors are more likely to take the substantial financial risk when making investment decisions. Moreover, the investors' lifecycle indicates that young investors tend to be more risk tolerant, results from this study confirms this statement. This study further indicated that high-income investors are more willing to take on financial risk whereas low-income investors are more risk-averse. The final factor investigated for this study was marital status. It can be concluded that married investors and no longer married investors are less risk tolerant than those never married. Results found to accord with previous international research results, only in a South African context. A significant contribution is made by this study in terms of profiling investors subjective risk tolerance levels in terms of demographic factors whereby financial institutions can offer more tailored investment options to their clients.

\section{References}

Ardehali, P. H., Paradi, J. C. \& Asmild, M. (2005). Assessing financial risk tolerance of portfolio investors using data envelopment analysis. International Journal of Information Technology and Decision Making, 4(3), 491-519.

Baker, H. K. \& Haslem, J. A. (1974). The impact of investor socio-economic characteristics on risk and return preferences. Journal of Business Research, 2(1), 469-476.

Blume, M. (1978). The changing role of the individual investor, New York: John Wiley.

Botwinick, J. (1966). Cautiousness in advanced age. Journal of Gerontology, 21(3), 347-353.

Coet, L. J. \& McDermott, P. J. (1979). Sex, instructional set, and group make-up: orgasmic and situational factors influencing risk-taking. Psychological Reports, 44(1), 1283-1294.

Cohn, R. A., Lewellen, W. G., Lease, R. C. \& Schlarbaum, G. G. (1975). Individual investor risk aversion and investment portfolio composition. Journal of Finance, 30(1), 605-620.

Creswell, J. W. (2014). Research design: quantitative, qualitative and mixed methods. 4th ed. United States: SAGE.

Crouhy, M., Galai, D. \& Mark, R. (2014). The essentials of risk management (2nd ed), New York, NY: McGrawHill Education.

Davey, G. \& Resnik, P. (2008). Risk tolerance, risk profiling and the financial planning process, Austrailia: FinaMetrica. 
Dickason, Z. \& Ferreira S. J. (2018). The effect of gender and age of financial risk tolerance of South African investors. Investment Management and Financial Innovations, 15(2), 1-8.

Gibson, R., Michayluk, D. \& Van de Venter, G. (2013). Financial risk tolerance: an analysis of unexplored factors. Financial Services Review, 22(1), 23-50.

Gilliam, J., Chatterjee, S. \& Grable, J. E. (2010). Measuring the perception of financial risk tolerance: a tale of two measures. Journal of Financial Counselling and Planning, 21(2), 30-43.

Goldstein, R. \& McElligott, J. (2014). Risk appetite. Discussion paper, Ireland: Central Bank of Ireland.

Grable, J. E. (2016). Financial risk tolerance. (In Xiao, J.J., ed. Handbook of Consumer Finance Research, Switzerland: Springer International Publishing, p. 19-31).

Grable, J. E. \& Joo, S. (1999). Factors related to risk tolerance: a further examination. Consumer interest annual, 45(1), 53-58.

Grable, J. E. \& Joo, S. (2004). Environmental and biopsychosocial factors associated with financial risk tolerance. Journal of Financial Counselling and Planning, 15(1), 73-82.

Grable, J. E. \& Lytton, R. H. (1998). Investor risk tolerance: testing the efficacy of demographics as differentiating and classifying factors. Financial Counselling and Planning, 9(1), 61-73.

Grable, J. E. \& Roszkowski, M. J. (2008). The influence of mood on the willingness to take financial risks. Journal of Risk Research, 11(7), 905-923.

Grable, J. E. (1997). Investor risk tolerance: testing the efficacy of demographics as differentiating and classifying factors, Blacksburg: Virginia. (Thesis-PhD).

Grable, J. E. (2000). Financial risk tolerance and additional factors that affect risk taking in everyday money matters. Journal of Business and Psychology, 14(2), 625-630.

Hanna, S. \& Chen, P. (1997). Subjective and objective risk tolerance: implications for optimal portfolios. Financial Counseling and Planning, 8(2), 17-25.

Hanna, S. D., Gutter, M. S. \& Fan, J. X. (2001). A measure of risk tolerance based on economic theory. Association for Financial Counseling and Planning Education, 12(2), 53-60.

Hawley, C. B. \& Fuji, E. T. (1993). An empirical analysis of preferences for financial risk: further evidence on the Friedman-Savage model. Journal of Post Keynesian Economics, 16(1), 197-204.

Higbee, K. L. \& Lafferty, T. (1972). Relationships among risk preferences, importance, and control. The Journal of Psychology, 81(1), 249-251.

Irwin, C. E. (1993). Adolescence and risk-taking: How are they related? (In Bell, N. J. \& Bell, R. W., eds. Adolescent risk taking, Newbury Park, CA: SAGE. p. 7-28).

Lazzarone, B. G. (1996). The economic well-being of rural Nevada elders. Proceedings of the 1996 conference of the western region home management family economics educators, p. 67-74.

Lee, H. K. \& Hanna, S. (1991). Wealth and stock ownership. Proceedings of the association for financial counselling and planning education, p. 126-140.

Louw, S. (2017). How to determine your risk tolerance.

MacCrimmon, K. R. \& Wehrung, D. A. (1986). Risk management, New York: The Free Press.

Malkiel, B. G. (1996). A Random Walk Down Wall Street, New York, NY: W.W. Norton \& Co.

Marshall, M. N. (1996). Sampling for qualitative research. Family Practice, 13(6), 522-525.

Mazumdar, S. (2014). Individual investment behaviour with respect to financial knowledge and investment risk preference: a study. International Journal on Management Research and Business Strategy, 3(2), 47-55.

Metherell, C. (2011). The impact of demographic factors on subjective financial risk tolerance: A South African study, Durban: University of KwaZulu-Natal. (Unpublished Thesis-Masters).

Morin, R. A. \& Suarez, F. (1983). Risk aversion revisited. The Journal of Finance, 38(1), 1201-1216.

Nguyen, T. M. L. (2015). The influence of financial risk tolerance and risk perception on individual investment decision-making in a financial advice context, Queensland University. (Thesis-Phd).

Okun, M. A. \& DiVesta, F. J. (1976). Cautiousness in adulthood as a function of age and instructions. Journal of Gerontology, 31(1), 571-576.

Old Mutual. (2015). Premiums \& Problems (109 th ed), Cape Town

Quinlan, C. (2011). Business research methods, China: Cengage Learning.

Rachev, S. T., Stoyanov, S. V. \& Fabozzi, F. J. (2011). Risk and uncertainty, Hoboken, N.J.: John Wiley and Sons Inc.

Rahmawati, M., Kumar, D., Kamuaya, M., Jamil, F. \& Muneer, S. (2015). Determinants of the risk tolerance of individual investors. International Journal of Economics and Financial Issues, 12(1), 373-378. 
Roszkowski, M. J., Snelbecker, G. E. \& Leimberg, S. R. (1993). Risk-tolerance and risk aversion. (In Leimberg, S. R., Satinsky, M. J., LeClair, R. T. \& Doyle, R. J., eds. The tools \& techniques of financial planning. $4^{\text {th }}$ ed. Cincinnati, OH: National, p. 1-656).

Rubin, P. H. \& Paul, C. W. (1979). An evolutionary model of tastes for risk. Economic Inquiry, 17(4), 585-596.

Rutgers. (2014). Investment risk tolerance quiz. http://njaes.rutgers.edu/money/riskquiz/ Date of access: 27 Aug. 2016.

Sahin, S. \& Yilmaz, Ö. (2009). Measuring risk tolerance: does the methodology matter? Paper presented at the Anadolu International Conference in Economics, Eskişehir, Turkey, 17-19.

Sharma, K. (2006). An insight into determinants of financial risk tolerance. SCMS Journal of Indian Management, 11(3), 12-23.

Slovic, P. (1966). Risk-taking in children: age and sex differences. Child Development, 37(4), 169-176.

Sung, J. \& Hanna, S. (1996). Factors related to household risk-tolerance: an ordered profit analysis. Consumer Interests Annual, 42(2), 227-228.

Tversky, A. \& Kahneman, D. (1981). The framing of decisions and the psychology of choice. Science, New Series, 211(4481), 453-458.

University of Missouri-Columbia. (2017). Life differences make women less risk tolerant when investing: researcher finds that women have unique financial needs that impact investment decisions.

Van de Venter, G., Michayluk, D. \& Davey, G. (2012). A longitudinal study of financial risk tolerance. Journal of Economic Psychology, 33(1), 794-800.

Van den Berg, B. (2004). Understanding financial markets and instruments (4th ed), Johannesburg: Eagle Rock Financial Services CC.

Van Dorresteijn, F. (2017). Which socio-demographic factors determine risk-taking behaviour of investors? Radboud University. (Thesis-Masters).

Van Schalkwyk, C. H. (2012). Member choice in a defined benefit contribution pension plan: decision-making factors, Johannesburg: University of Johannesburg. (Unpublished Thesis-PhD).

Vaughan, E. J. \& Vaughan, T. M. (2008). Fundamentals of risk and insurance (10th ed), Hoboken, NJ: John Wiley \& Sons Inc.

Vroom, V. H. \& Pahl, B. (1971). Relationship between age and risk-taking among managers. Journal of Applied Psychology, 55(2), 399-405.

Wang, H. \& Hanna, S. (1997). Does risk tolerance decrease with age? Financial Counselling and Planning, 8(2), 27-32.

Warren, W. E., Stevens, R. E. \& McConkey, C. W. (1990). Using demographic and lifestyle analysis to segment individual investors. Financial Analysts Journal, 46(2), 74-77.

Yip, U. Y. (2000). Financial risk tolerance: a state or a trait? University of New South Wales. (Thesis-Masters).

Zhong, L. X. \& Xiao, J. J. (1995). Determinants of family bond and stock holdings. Financial Counselling and Planning, 6(1), 107-114. 